\title{
Direitos Humanos, Educação Inclusiva e EJA: quando uma proposta curricular se torna instrumento de luta e resistência
}

\author{
Human Rights, Inclusive Education and EJA: when a curricular proposal \\ becomes an instrument of fight and resistance
}

Amanda Sousa Batista do Nascimento

Doutoranda em Educação

Universidade Nove de Julho amandasousabatista1987@gmail.com

(iD) Celso Carvalho

Doutor em Educação

PPGE/Universidade Nove de Julho

cpfcarvalho@gmail.com

Resumo: O texto apresenta dados de pesquisa em curso cujo objeto de estudo é a educação especial e de jovens e adultos, entendida como parte do direito à educação para todos. Problematiza como os estudantes, à luz das desigualdades e preconceitos que marcam suas vidas, foram impediram de gozar de seu direito. Esses estudantes, Público-Alvo da Educação Especial (P.A.E.E.) e da Educação de Jovens e Adultos, vivenciam grandes dificuldades em razão dos desdobramentos produzidos pelas Políticas Educacionais no Brasil. O texto discute a Base Nacional Comum Curricular (BNCC), especificamente a forma como a EJA e os estudantes P.A.E.E foram excluídos do debate, o que nos leva à seguinte questão: a quem serve de fato a BNCC? Por fim, apresenta exemplo de prática pedagógica curricular, planejada por professores críticos e mostra como a referida prática se tornou instrumento de luta e resistência para os alunos.

Palavras-chave: Políticas Educacionais Inclusivas. Currículo. BNCC. EJA. Direito.

Abstract: The text presents data from ongoing research, which has as its object of study special educationand youth and adults, understood as part of the right to education for all. It questions howstudents, in the light of the inequalities and prejudices that mark their lives, have preventedthem from enjoying their rights. These students, Target Audience of Special Education (T.A.S.E.), in Portuguese call of P.A.E.E. and Youth and Adult Education, experience great difficulties due to the consequences produced by Educational Policies in Brazil. The text discusses the Common Base National Curriculum (CBNC), in Portuguese call of BNCC specifically the way in which EJA and P.A.E.E students were excluded from the debate, which leads us to the following question: who does BNCC really serve? Finally, it presents an example of curricular pedagogical practice, planned by critical teachers and shows how that practice has become an instrument of struggle and resistance for students.

Keywords: Inclusive Educational Policies. Curriculum. BNCC. EJA. Right. 


\title{
Introdução
}

Garantir o acesso aos espaços escolares e aos conteúdos curriculares pertinentes a cada etapa de ensino dos estudantes com deficiência não tem sido tarefa fácil e o mesmo pode-se dizer em relação à permanência. Esses estudantes, conforme regulamenta a Política Nacional de Educação Especial na Perspectiva da Educação Inclusiva (2008), Público-Alvo da Educação Especial, serão mencionados doravante como estudantes/educandos P.A.E.E.

A política educacional inclusiva percorreu um longo trajeto de idas e vindas, até chegar na atual Política Nacional de Educação Especial na Perspectiva da Educação Inclusiva de 2008. Importante lembrar que essa política se trata, em verdade, de um documento norteador e não uma política de Estado.

\begin{abstract}
A Política Nacional de Educação Especial na Perspectiva da Educação Inclusiva (MEC, 2008), com validade em todo o território brasileiro, orienta os programas e ações nesta área para promover o acesso e a permanência de alunos com deficiência, transtornos globais do desenvolvimento e altas habilidades/superdotação, público-alvo da Educação Especial, no ensino regular, ampliando a oferta do atendimento educacional especializado, rompendo com o modelo de integração em escolas e classes especiais a fim de superar a segregação e exclusão educacional e social das pessoas com deficiência. É uma Política Pública Educacional, que perpassa e transita pelo campo de Políticas Públicas Inclusivas, ou Políticas de Ação Afirmativa. Os defensores das políticas públicas de ação afirmativa para a sociedade 136onhec seus objetivos sem associá-las somente a medidas circunstanciais de emergência para as demandas latentes da população, procurando também questionar o passado de segregação e injustiça social que deixou resquícios vivenciados no presente e planejar um futuro consciente com mais respeito aos direitos de todos, cada qual com sua singularidade. (NASCIMENTO, 2018, p.61-62)
\end{abstract}

No Brasil, o cenário educacional de constantes modificações na estrutura do Ministério da Educação e Cultura (MEC), decorrente das trocas governamentais, cria uma situação de profunda instabilidade. Não temos políticas educacionais de Estado, mas de governos. Nesse contexto, a ameaça ao caráter democrático, laico e gratuito da escola pública, disseminada por grupos que defendem interesses econômicos de viés neoliberal, é uma marca presente na educação brasileira há décadas. Recentemente, a onda conservadora que, a cada dia, demarca territórios e lugares de fala nas discussões pedagógicas atuou de forma incisiva na recente reforma curricular, propondo questões e temas que visam definir o que ensinar e como ensinar, desde a primeira infância até o ensino médio. Estamos falando da ação desses grupos no processo de elaboração e implementação da Base Nacional Comum Curricular (BNCC), instituída pela Resolução CNE /CP n², de 22 de 
dezembro de 2017, que define o currículo ao longo das etapas e respectivas modalidades no âmbito da educação básica.

Em razão do cenário acima exposto, a questão que tem orientado nossa investigação visa a saber como tem ocorrido a garantia do acesso e da permanência aos educandos P.A.E.E. no contexto da BNCC. Tal questão tem como fundamento o fato de que, desde a educação infantil até a educação de jovens e adultos (EJA), a Base Nacional Comum Curricular excluiu em sua versão final, materiais específicos e subsídios para estudantes deficientes e professores, de modo a atender as especificidades e singularidades inerentes a este público-alvo.

Tendo em vista que essa questão deriva de ações recentes, especificamente as que definiram nova forma de organização curricular, faremos uma breve incursão por esse debate, procurando problematizar a BNCC no contexto.

\section{Currículo: pista de corrida que delimita quem fica e quem sai}

De acordo com Silva (2003), a palavra currículo vem do latim curriculum, pista de corrida e, nesse sentido, ao longo dessa corrida, que poderíamos associar ao percurso escolar de um indivíduo norteado pelo currículo, a identidade desse indivíduo é construída e o forma. É a partir deste currículo que o educando se constitui.

É por meio do currículo, concebido como elemento discursivo da política educacional, que os diferentes grupos sociais, especialmente os dominantes, expressam sua visão de mundo, seu projeto social, sua verdade (SILVA, 2003, p.10)

Para Silva, o currículo possui caráter expressivo de ideologias de mundo e aspirações sociais. Por isso, ao longo dos anos, os estudiosos do currículo não se limitaram a desenvolver teorias apenas no campo epistemológico e enfatizaram questões como a natureza humana, natureza do conhecimento, da cultura e da sociedade.

A questão curricular é um ponto importante em nossa pesquisa, à medida que se nota a ausência de desenhos curriculares específicos para o público-alvo da Educação Especial na Perspectiva Inclusiva e para a EJA. A BNCC excluiu essas modalidades de ensino. Não temos, portanto, nenhuma orientação curricular oficial que indique as especificidades dessas modalidades, nem orientações que delimitem um plano para a formação de professores para elas. No documento da BNCC, a questão assim se apresenta: 
Referência nacional para a formulação dos currículos dos sistemas e das redes escolares dos Estados, do Distrito Federal e dos Municípios e das propostas pedagógicas das instituições escolares, a BNCC integra a política nacional da Educação Básica e vai contribuir para o alinhamento de outras políticas e ações, em âmbito federal, estadual e municipal, referentes à formação de professores, à avaliação, à elaboração de conteúdos educacionais e aos critérios para a oferta de infraestrutura adequada para o pleno desenvolvimento da educação. [...] É imprescindível destacar que as competências gerais da Educação Básica, apresentadas a seguir, inter-relacionam-se e desdobram-se no tratamento didático proposto para as três etapas da Educação Básica (Educação Infantil, Ensino Fundamental e Ensino Médio), articulando-se na construção de conhecimentos, no desenvolvimento de habilidades e na formação de atitudes e valores, nos termos da LDB. (BRASIL, 2017, p.8-9)

A partir desse vácuo, o que temos visto é uma série de ações que colocam em risco os avanços e conquistas da educação especial e de jovens e adultos. São tentativas de retrocesso educacional, como o Projeto de Lei (PL nº. 3.803/2019) que institui modificações na Política Nacional de Educação Especial na Perspectiva da Educação Inclusiva (2008), que passaria a ser denominada Política Nacional para Educação Especial e Inclusiva, prevendo a "criação ou revitalização de centros de convivência voltados para inclusão de pessoas com Transtorno do Espectro Autista, Deficiência Mental e Deficiências Múltiplas”. (SENADO FEDERAL, 2019, p.6)

O referido projeto de lei, ao propor a criação ou revitalização de centros de convivência voltados exclusivamente para a inclusão de pessoas com deficiência, retrocede nas lutas históricas e sociais pelo direito à educação das pessoas com deficiência no ensino regular. Voltar a segregar os educandos com qualquer tipo de deficiência, apartando-os dos demais estudantes sem deficiência, é uma proposta que contraria princípios estabelecidos em âmbito nacional e internacional acerca da Educação Especial e Inclusiva. Tal proposta tramita no Senado Brasileiro, atualmente na Comissão de Direitos Humanos e Legislação Participativa do Senado.

Nessa mesma linha de retrocessos, temos o movimento de discussão, redação e aprovação da nova BNCC iniciado em 2015. No início, a crítica maior era acerca do caráter centralizador e universal da referida proposta. Inúmeros pesquisadores, educadores e especialistas na área da educação criticaram a proposta centralizadora, especificamente porque ela veio acompanhada em uma perspectiva "alicerçada nas avaliações em larga escala e balizadora dos programas governamentais de livros didáticos” (CÁSSIO, 2019, p.13).

No cenário educacional brasileiro, tivemos um amplo debate no início. Ao final, o resultado não foi o esperado pela maioria dos profissionais da educação. Propostas quase consensuais para a Educação Infantil e para o Ensino Fundamental, surgidas de amplo debate, três versões do documento e consulta pública, foram quase que totalmente abandonadas em razão do golpe de 
2016. A mudança política mudou o cenário de elaboração da BNCC. Nova equipe, novos procedimentos, novas orientações, novos princípios e fundamentos. Nesse cenário, versões embargadas pelo Conselho Nacional de Educação em 2017 e 2018 e a discussão de uma proposta curricular para o Ensino Médio feita de forma apartada por delegação do MEC, criaram uma situação que rompe "com a definição de Educação Básica que está na Lei de Diretrizes e Bases da Educação Nacional (LDB, Lei n. 9.394/1996)". (CASSIO, 2019, p. 14)

Tanto o Projeto de Lei (PL n ${ }^{\circ}$. 3.803/2019) quanto a BNCC nos alertam para a necessidade de continuidade da luta pelos Direitos Humanos. Os estudantes com deficiência que, em sua grande maioria, estão se tornando público-alvo da Educação de Jovens e Adultos, foram segregados no momento de discussão e tiveram seus direitos de aprendizagem comprometidos, pois a BNCC não respeita as singularidades e especificidades inerentes a cada etapa e modalidade de ensino.

A fala do ministro da educação, ao apresentar a BNCC em 2017, esclarece as intenções mais amplas do documento:

O ministro da educação, na apresentação da proposta publicada e pronta para o "consumo" nos espaços escolares, diz que se trata da "implementação de uma política educacional articulada e integrada", que se coloca como ferramenta para "adequar" os currículos em nível federal. A palavra "adequar" tem um peso político, ela traz um sentido específico nesse discurso, que é o de "formatar" a partir de uma lógica específica. (VIEIRA, 2019, p.309)

Diante da perplexidade que essas ações ensejam, é necessário fortalecer a disputa em torno das políticas educacionais e garantir o acesso aos direitos definidos pela Constituição Federal para todos. A inclusão social, educacional e cultural deve ser foco do debate e da disputa no âmbito educacional. Se o currículo é um documento de identidade, as disputas que o envolvem são fundamentais para garantir, ou não, o direito constitucional de Educação para todos.

Entendemos que o currículo deve ser visto como uma forma de política cultural, assim como a escola, em que experiências e subjetividades são contestadas e, ao mesmo tempo, atividades são produzidas em favor da transformação, contra a dominação e a opressão. Por isso faz sentido perguntar a quem serve uma proposta curricular cujo discurso "oficializa o objetivo de conviver e aprender com as diferenças e diversidades" (VIEIRA, 2019, p.309), mas ao mesmo tempo se apresenta repleta de discursos prontos, vendidos, elaborados e construídos a partir de interesses de grandes grupos empresariais que apoiaram a aprovação da BNCC? Interesses de cunho econômico, que de maneira alguma privilegiam os educandos, se apoderaram do debate e impuseram sua narrativa. 
Tratando especificamente da Educação de Jovens e Adultos (EJA), Catelli Jr. (2019) enfatiza que, desde a primeira versão, a BNCC não apresenta qualquer proposta referente aos educandos público-alvo dessa modalidade de ensino, um grupo enorme de pessoas que não tiveram acesso e permanência ao Ensino Fundamental e Médio na idade certa e, posteriormente, precisam acessar a escola para a conclusão de seus estudos.

Não houve nenhum texto que problematizasse a especificidade da modalidade, considerando a diversidade de sujeitos que se matriculam nas escolas de EJA de todo o país. A reflexão necessária, com base nas experiências e conhecimentos produzidos, sobre qual currículo seria adequado para pessoas que deixaram a escola e retornam a ela na fase adulta, tendo já acumulado experiências e aprendizagens significativas nos âmbitos pessoal e profissional, não foi feita (CATELLI JR., 2019).

O golpe de 2016 criou um cenário adverso ao debate. Abriu caminho para ataques constantes aos órgãos oficiais que fomentam a ciência e a pesquisa no Brasil e aos documentos oficiais de cunho democrático e progressista produzidos na última década. A contaminação do debate educacional e político em decorrência da ascensão ao poder de grupos conservadores vem sendo a tônica. Diante disso:

A inclusão da EJA na BNCC não seria de pronto a solução para que tivéssemos
avanços significativos na modalidade. Entretanto, a ausência completa de
propostas e o esvaziamento da Secretaria de Educação Continuada,
Alfabetização, Diversidade e Inclusão do MEC (SECADI/MEC) a partir de
2016, com a chegada de Michel Temer à presidência, vêm apenas reforçando o
lugar marginal da Educação de Jovens e Adultos no país. (CATELLI JR., 2019,
315-16)

O currículo, ponto central de uma política educacional que define quais conteúdos e quais temas serão abordados no contexto da sala de aula, deveria, por sua própria gênese, fomentar de maneira crítica a preparação dos professores para formar sujeitos autônomos, críticos, criativos e comprometidos com a democracia e a justiça social. Esses, como pesquisadores em ação, são agentes fundamentais na luta pela transformação educacional, pelo fortalecimento do poder individual e coletivo, ou seja, para a construção de uma sociedade mais ampla.

A ação dos professores, como intelectuais e transformadores, fundamentada em princípios morais e éticos, preocupada com o sofrimento e as lutas dos oprimidos, é fundamental para a reformulação do campo curricular, especialmente nesse momento em que interesses de diferentes agentes políticos, religiosos e empresariais, que nem sempre têm como prioridade a garantia de assegurar o direito à educação para todos, pois suas prioridades possuem viés meritocrático e individualista, assumiram o controle do debate. Contudo, a ação docente não pode se limitar a 
esperar modificações significativas na BNCC ou esperar mudanças efetivas do poder público. Ressignificar as práticas escolares como formas de resistência a favor da continuidade da luta pelo direito à Educação, principalmente quando o lugar de fala é o do próprio educando, se torna uma estratégia de luta. É o que trataremos na segunda parte desse texto.

A resistência e luta dos professores e educandos do chão da escola: pelo direito ao currículo, ao acesso e a permanência na escola

O relato de experiência a seguir percorreu esta ideia, em concordância com o conhecido lema Nada Sobre Nós, Sem Nós, que ganhou notoriedade em 2001. O lema tem origem na experiência desenvolvida pelo Grupo de Usuários de Estratégias, do Ministério da Saúde da Grã-Bretanha. Formado por pessoas com dificuldades de aprendizagem, de diversas organizações, adotou o lema Nada Sobre Nós, Sem Nós e passou a exigir que pessoas com dificuldade de aprendizagem tivessem acesso a todos os serviços públicos: saúde, emprego, serviços sociais, habitação, associações de habitação, consumidores de serviços, fornecedores de serviços, inspeção e outros (SASSAKI, p.20).

O trabalho que deu origem a esse relato foi desenvolvido no $4^{\circ}$ bimestre letivo (período compreendido entre outubro e dezembro/2018) com duas turmas de EJA. Os alunos se encontravam na faixa etária compreendida entre 19 a 82 anos, em um Centro Público de Formação Profissional (C.P.F.P.) chamado Maria Lacerda de Moura, localizado no Jardim do Estádio, na cidade de Santo André-SP. A referida Unidade Escolar pertence à Rede Municipal de Ensino da cidade.

A maioria dos estudantes regularmente matriculados nessas turmas eram P.A.E.E., apresentando diferentes deficiências: intelectual, física, visual, múltipla, baixa visão, mobilidade reduzida e transtorno do espectro autista. Esses estudantes apresentavam trajetória educacional demarcada por experiências de exclusão, presentes na fala dos próprios educandos quando nos relatavam suas trajetórias. Nessa modalidade de ensino na rede municipal de Santo André, trabalhamos sob a égide do currículo integrado, isto é, uma concepção de ensino que abrange a compreensão global do conhecimento e almeja promover a interdisciplinaridade no processo de ensino e aprendizagem.

Quando informados de que haveria o fechamento da referida Unidade Escolar, implicando a transferência involuntária dos educandos para outra unidade escolar, mais distante da residência deles, foi nítida a fragilização do grupo de alunos. Alguns deles tinham a consciência de que não conseguiriam o acesso à nova escola, para dar continuidade aos seus estudos, em razão da distância de suas residências. Mais uma barreira, entre tantas outras já percorridas, a impedir o acesso e permanência destes sujeitos à educação, a impedir o exercício do direito à educação. 
Partindo da situação-problema dos alunos daquele Centro Público, os professores decidiram instrumentalizar os educandos com o conhecimento acerca de seus direitos, para que se conscientizassem e os utilizassem como ferramentas no exercício da cidadania e na luta por seus direitos. Para realizar a contextualização do trabalho pedagógico e planejamento das atividades curriculares nessa proposta, os professores se ampararam nos documentos municipais já produzidos na rede que relatavam todo o percurso histórico dessa modalidade de ensino na Rede Municipal de Santo André.

Historicamente, a educação especificamente pensada e organizada para jovens e adultos desenvolveu-se ao longo do processo de resistência à ditadura de 1964 nas discussões de inúmeras experiências realizadas pelos movimentos populares e pelos trabalhadores. Em 1989, a Câmara Municipal da cidade aprovou várias reformas na estrutura administrativa e definiu que o Serviço de Educação de Jovens e Adultos (SEJA) ficaria subordinado à Secretaria de Educação e Cultura, a quem caberia "atender à alfabetização dos que não haviam completado a escolarização básica" (RODRIGUES, 2016, p.58).

Nesse contexto, a EJA em Santo André surgiu e se consolidou juntamente com outros movimentos de gênese na Educação Popular, como o MOVA. Na perspectiva de que a educação é um direito social, no ano de 2014, a cidade de Santo André recebeu "o selo de Cidade Livre do Analfabetismo, concedido pelo Ministério da Educação às cidades que alcançaram a meta de 96\% da população com mais de 15 anos alfabetizada" (RODRIGUES, 2016, p.146).

Esse processo vivido pelo munícipio e sua busca em combater o analfabetismo foi contemplado por ações recentes durante a discussão e elaboração dos planos municipais de educação, desdobramento do plano nacional e estadual. O que se percebeu nesse momento foi que:

Esta concepção de educação também orientou a elaboração do Plano Municipal de Educação (PME), movimento que mobilizou os educadores de todas as modalidades de ensino da rede. O PME cuja vigência é 2015-2025 foi aprovado no ano de 2015, tendo força de lei, possui papel fundamental para a consolidação dos princípios norteadores das políticas educacionais da cidade de Santo André, visto que, estabelece metas que buscam a ampliação do direito à educação e protege as mesmas de descontinuidade política com a troca de gestões administrativas. (NASCIMENTO; RUBIRA, 2019, p.219-220)

A EJA, por sua diversidade cultural e socioeconômica, sinaliza a urgência de um novo olhar para o planejamento e formação continuada dos professores nessa modalidade de ensino. Diante da situação e com todo o contexto escolar, histórico e social daqueles educandos e levando-se em consideração o fato de que a EJA, por si só, já faz parte da Educação Inclusiva, o projeto desenvolvido possuía grande legitimidade. 


\section{Dialogia}

NASCIMENTO, Amanda Sousa Batista do; CARVALHO, Celso. Direitos Humanos, Educação Inclusiva e EJA: quando uma proposta curricular se torna instrumento de luta e resistência

O infográfico abaixo exemplifica um pouco do que estamos tratando quando nos referimos às especificidades do público alvo da EJA:

Figura 1 - Círculo vicioso entre a Pobreza e Deficiência

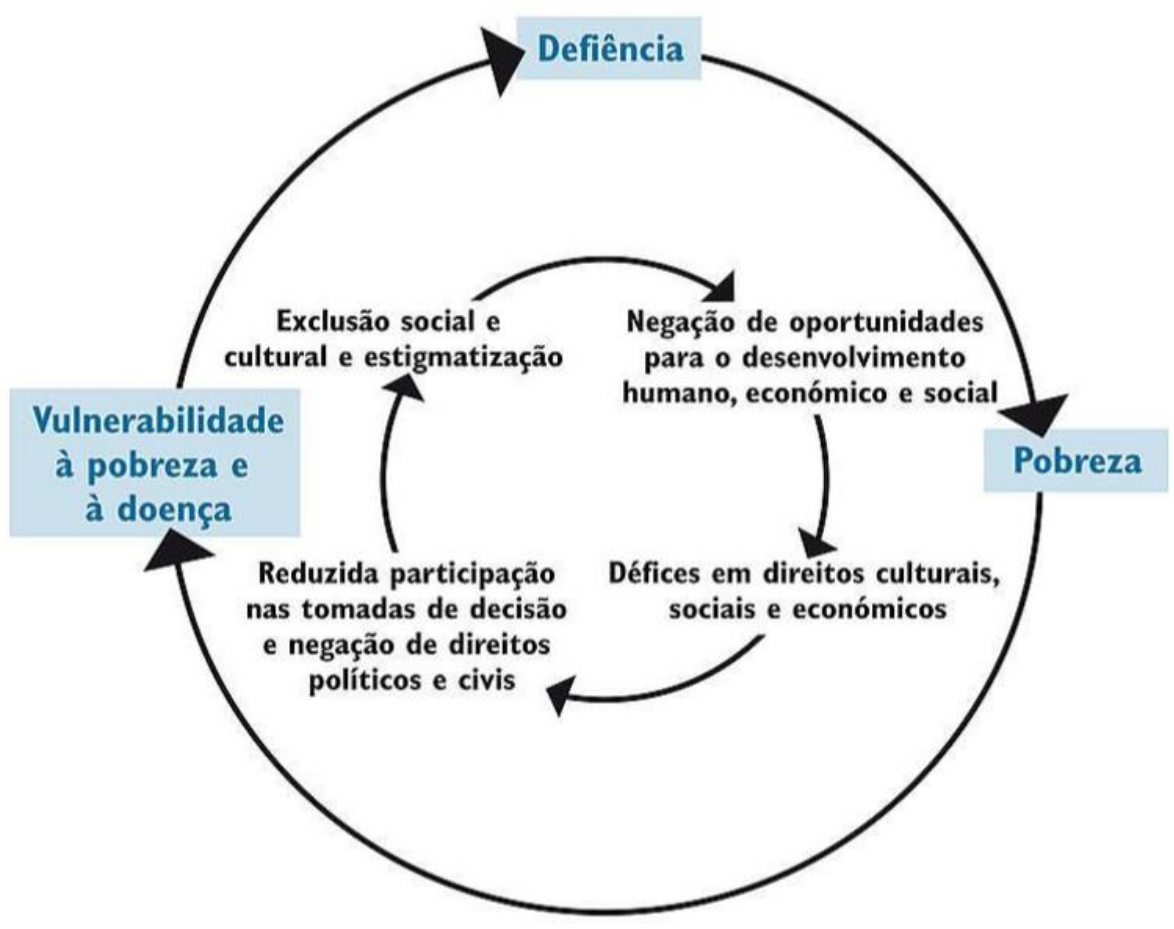

Fonte: DFID, 2000. Disponível em: http://www.making-prsp-inclusive.org/ - Acesso em: 21 ago. 2020.

\section{Materiais e Métodos}

O planejamento dos professores propôs uma sequência de atividades com o objetivo principal de propiciar aos estudantes que ainda não tinham conhecimento dos seus direitos de cidadãos a 143onhece-los e, assim, iniciar com o grupo um processo que lhes possibilitasse a consciência acerca dos seus direitos fundamentais como cidadão, pessoa idosa e pessoa com deficiência. Os conteúdos curriculares abordados foram as legislações vigentes sobre os direitos da pessoa idosa, da pessoa com deficiência, direitos humanos, jogos dramáticos e produção textual com uso de diferentes recursos e portadores textuais não convencionais.

Como estratégias pedagógicas, foram realizadas semanalmente rodas de conversa sobre conhecimentos prévios e vivências relacionadas a direitos, a confecção de cartazes com imagens relacionadas aos temas, a apresentação do tema Direitos Humanos com o apoio de recursos 
midiáticos, além de dinâmicas com interpretação de gravuras relacionadas ao tema Rede de Proteção e jogos dramáticos nos quais os alunos criaram cenas corporais, que retratavam situações relacionadas aos direitos e que foram fotografadas pelas professoras.

Os registros fotográficos produzidos a partir dos jogos dramáticos fizeram parte de uma exposição no saguão da Prefeitura Municipal de Santo André com início no dia 03 de dezembro de 2018. Disponível à visitação pública, no dia da abertura os alunos estiveram presentes, explicando as diferentes etapas do projeto desenvolvido até chegar ao produto exposto. Nessa ocasião, os educandos puderam explicitar aos visitantes da exposição pública qual o objetivo daquele trabalho e a causa pela qual estavam lutando: seu direito à Educação.

\section{Conclusões}

O relato de experiência acima detalhado permitiu observar o processo pelo qual os estudantes passaram do luto pelo fechamento de suas salas e pela restrição à sua oportunidade de estudar à luta, ao sentimento de pertencimento e protagonismo, à consciência de seu lugar de fala. Essa mudança foi possível pelo planejamento pedagógico que os levou ao conhecimento necessário, carregado de vivências com dimensões antropológicas, políticas e culturais, possibilitando a participação social e cidadã, uma experiência transformadora e afirmativa sobre o poder de atuação e inclusão.

Kramer (1982) já alertava para os perigos de se pensar em políticas educacionais com caráter compensatório ou amparadas na ideia equivocada de que os estudantes público-alvo de políticas educacionais inclusivas são fracassados, produto de privação cultural e precisam de estratégias diferenciadas para terem o minimo de sucesso possivel. Nesse caso, incluem-se não somente os estudantes com deficiência, mas os educandos com transtornos funcionais específicos, estudantes público-alvo da Educação de Jovens e Adultos, entre tantos outros educandos que são afetados pela desigualdade e mazelas sociais, que se encontram em situação de vulnerabilidade social.

Muitos projetos educacionais ao longo do tempo, objetivando permitir a inclusão, mas fundados na lógica capitalista, se mostraram incapazes que alcançar qualquer resultado expressivo. O processo capitalista, que almeja incluir por um modo, desenraiza e exclui de outro modo. Segue suas próprias regras, sua própria lógica. É contraditório, mesmo quando procura não ser. Segundo José de Souza Martins (1997, p. 37), 
[...] uma alternativa includente provoca necessidade de resolver, de criticar, de recusar a exclusão desta nossa sociedade, a recusa, sobretudo, da dupla sociedade, uma sociedade daqueles que só tem obrigações de trabalho e não tem absolutamente mais nada, e uma sociedade daqueles que tem em princípio absolutamente tudo, e nenhuma responsabilidade pelo destino dos demais.

Por fim, a prática educativa relatada mostrou que a inclusão é um processo que implica conhecimento dos direitos, mas não apenas isso. Implica também mudança de postura, de professores e alunos. A postura dos alunos mudou. Seus discursos, ao resgatarem a importância "dos direitos do idoso, do direito de ter uma família, de ter um trabalho", evidenciaram o significado de terem seu trabalho reconhecido, apresentado em uma exposição aberta, com visitação pública. Para os professores, mostra que o trabalho com o currículo integrado permite que os alunos vivam o processo de adaptação à nova escola de forma tranquila, permitindo a aquisição de novos conhecimentos, o aprimoramento das atividades de vida independente e de autonomia.

Infelizmente, nem todos os educandos que estudavam nas turmas do C.P.F.P. Maria Lacerda de Moura conseguiram se matricular na escola que lhes foi oferecida e tal cenário reforça o quanto precisamos discutir a Educação como Direito Humano e Social de todos.

\section{Referências}

ANDRÉ, SANTO. Lei Orgânica do Município/1990. Disponível em: http://www.cmsandre.sp.gov.br/lom.html Acesso em 27/03/2020.

BRASIL. Presidência da República. Constituição da República Federativa do Brasil de 1988. Disponível em: http://www.planalto.gov.br. Acesso em: mar. 2020.

BRASIL. Ministério da Educação. Base Nacional Comum Curricular. Disponível em: http://basenacionalcomum.mec.gov.br/a-base. Acesso em 27/03/2020.

BRASIL. Ministério da Educação. Resolução CNE/CP n 2, de 22 de dezembro de 2017.

CÁSSIO, Fernando. Existe vida fora da BNCC? CÁSSIO, F.; CATELLI JR, R. Educação é a Base? 23 Educadores discutem a BNCC. São Paulo: Ação Educativa, 2019.

CATELLI JR, Roberto. O não-lugar da Educação de Jovens e Adultos na BNCC. In: CÁSSIO, F.; CATELLI JR, R. Educação é a Base? 23 Educadores discutem a BNCC. São Paulo: Ação Educativa, 2019.

FREIRE, Paulo. Pedagogia da autonomia: saberes necessários à prática educativa. Rio de Janeiro: Paz e Terra, 1997.

FRIGOTTTO, Gaudêncio; CIAVATT'TA, Maria; RAMOS, Marise. A gênese do Decreto $\mathbf{n}^{\circ}$ 5.154/2004: um debate no contexto controverso da democracia restrita. In: FRIGOTTO. 
Gaudêncio; CIAVATTA, Maria; RAMOS, Marise. (Org.). Ensino Médio Integrado: Concepções e Contradições. $2^{\text {a }}$ Ed. São Paulo: Cortez, 2010.

FREIRE, Paulo. Pedagogia da autonomia: saberes necessários à prática educativa. Rio de Janeiro: Paz e Terra, 1997.

FREIRE, Paulo. Pedagogia do oprimido. 17. ed. Rio de Janeiro: Paz e Terra, 1987.

KRAMER, Sonia. Privação cultural e educação compensatória: uma análise crítica. Cadernos de pesquisa, n. 42, p. 54-62, 2013

MARTINS, José de Souza. Exclusão social e a nova desigualdade. São Paulo: Paulus, 1997.

NASCIMENTO, Amanda Sousa Batista do. A política nacional de educação especial na perspectiva da educação inclusiva: o processo de implementação na rede municipal de Santo André (2008-2016). Dissertação de Mestrado, Universidade Nove de Julho, São Paulo, 2018.

NASCIMENTO, A.S.B.; RUBIRA, C. B. A Conscientização de seus Direitos Fundamentais, enquanto Pessoa Humana: uma Proposta Inclusiva na EJA. In: Vozes da Educação. ${ }^{\circ}$ ed.São Paulo: Diálogo Freriano, 2019, v.1, p. 219-20.

RAMOS, Marise. Possibilidades e desafios na organização do currículo integrado. In: FRIGOTTOO. Gaudêncio; CIAVATTA, Maria; RAMOS, Marise. (org.). Ensino Médio Integrado: Concepções e Contradições. $2^{a}$ Ed. São Paulo: Cortez, 2010.

RODRIGUES, Marly. Tecendo vivências: a educação de jovens e adultos Santo André, 1989-2016. Santo André, SP: Prefeitura Municipal de Santo André, 2016.

SASSAKI, Romeu Kazumi. Nada sobre nós, sem nós: Da integração à inclusão - Parte 2. Revista Nacional de Reabilitação, ano X, n. 58, set./out. 2007, p.20-30.

SENADO FEDERAL, Projeto de Lei -PL 3.803/2019. Disponível em: https://www25.senado.leg.br/web/atividade/materias/-/materia/137500

SILVA, Tomaz Tadeu da. Documentos de identidade: uma introdução às teorias do currículo. 3. ed. Belo Horizonte: Autêntica Editora, 2003.

VIEIRA, Claudia Regina. Qual o lugar da Educação Especial na BNCC? CÁSSIO, F.; CATELLI JR, R. Educação é a Base? 23 Educadores discutem a BNCC. São Paulo: Ação Educativa, 2019. 


\section{Dialogia}

NASCIMENTO, Amanda Sousa Batista do; CARVALHO, Celso. Direitos Humanos, Educação Inclusiva e EJA: quando uma proposta curricular se torna instrumento de luta e resistência

Recebido em: 31 mar. 2020/ Aprovado em: 13 maio 2020

\section{$\underline{\text { Cite como }}$}

\section{(ABNT NBR 6023:2018)}

NASCIMENTO, Amanda Sousa Batista do; CARVALHO, Celso. Direitos Humanos, Educação Inclusiva e EJA: quando uma proposta curricular se torna instrumento de luta e resistência. Dialogia, São Paulo, n. 35, p. 135-147, maio/ago. 2020. Disponível em: https://doi.org/10.5585/dialogia.n35.16938.

\section{American Psychological Association (APA)}

Nascimento, A. S. B., \& Carvalho, C. (2020, maio/ago.). Direitos Humanos, Educação Inclusiva e EJA: quando uma proposta curricular se torna instrumento de luta e resistência. Dialogia, São Paulo, 35, p. 135-147. https://doi.org/10.5585/dialogia.n35.16938. 